\title{
Decision Support System for the Assessment and ranking of Energy Generation Technologies
}

\author{
${ }^{1}$ Jurate Sliogeriene, ${ }^{2}$ Arturas Kaklauskas, ${ }^{3}$ Romualdas Kliukas, ${ }^{4}$ Zenonas Turskis, ${ }^{5}$ Natalija \\ Lepkova, ${ }^{6}$ Arunas Komka \\ ${ }^{1}$ Vilnius Gediminas Technical University, Sauletekio al. 11, LT-10223 Vilnius, Lithuania, \\ E-mail jurate.sliogeriene@vgtu.lt \\ *2,Corresponding Authors Vilnius Gediminas Technical University, Saulètekio al. 11, LT-10223 \\ Vilnius, Lithuania,E-mail jurate.sliogeriene@vgtu.lt, arturas.kaklauskas@vgtu.lt; \\ 2,3,4,5,6 Vilnius Gediminas Technical University, Saulètekio al. 11, LT-10223 Vilnius, \\ Lithuania
}

\begin{abstract}
Article presents a priority determination and utility analysis of energy generation technologies; it was done with the help of AHP and COPRAS, mathematical multi-criteria methods, and the EGT-SELECT-DS, a decision support system based on these methods. The research results suggest that the assessment and choice of energy generation technologies using multi-criteria methods and DSS is a good way to combine the performance criteria, cost-effectiveness, and ecological integrity with the criteria of technological innovativeness, socially responsible operation and sustainable development. The main objective and novelty of the paper is developed MCDM DSS in which are aggregated two different methods.
\end{abstract}

Keywords: decision support system, energy technologies, multi-criteria analysi.

\section{Introduction}

Multi-criteria decision-making methods (MCDM) are often applied to solve problems that aim to find which of the alternative options under analysis is the best solution [1]. In the past, MCDS methods helped assess how well infrastructure companies were managed [2],[3], evaluate project risks [4], reconcile infrastructure investments and environmental resolutions [5] and select technical solutions for energy-efficient homes, and the best alternatives of facilities management [6]. Multicriteria methods are an attempt to pick an optimal solution assessing the alternative options by several contradictory criteria at the same time.

As tools to analyse energy-sector issues, MCDM methods were introduced in the 1970s. The development and use of MCDM tools in energy-sector decision-making were primarily determined by the liberalisation of energy markets, implementation of the principles of sustainable development, involvement of stakeholder groups in energy-sector decisionmaking, and the attempts to make sure the general public was represented in policy making. An analysis of literature revealed that, in the energy industry, MCDM tools are most often used to address such issues as energy policies and relevant environmental aspects, but rarer to analyse the choice of energy generation technologies [7],[8],[9].

One advantage of MCDM tools is that they make it possible to make an integrated assessment of both qualitative and quantitative criteria that define alternatives. Technologyassisted handling of multi-criteria problems allows to expand the scope by choosing any desired number of alternatives and their criteria, and to design universal automated decision support systems (DSS) in tune with the problem's goals.

This article presents the EGT-SELECT-DS, a DSS for the assessment of energy generation technologies (EGT) and the analysis of the impact of environment factors. The article also presents the results of the assessment of EGT. 


\section{The technique of algorithm design for our DSS}

To create a DSS for the assessment of EGT and the analysis of environment factors, the following key objectives were addressed step by step:

1) Selecting multi-criteria methods that are the most appropriate when a problem deals with the choice of EGT. In scientific researches, the issues of the energy industry are mostly analysed with the help of such methods as AHP, PROMETHEE, ELECTRE, ELECTRE III, ELECTRE IV, TOPSIS, and VIKOR [10],[11],[12]. To build a wider decisionmaking platform and to make the results more reliable, scientists recommend applying several methods to solve a single problem.

AHP (Analytic Hierarchy Process) and COPRAS (Complex Proportional Assessment method) [13],[14] are the methods applied to solve a problem dealing with the comparison of EGT and the analysis of environment factors in the context of Lithuania.

2) Generating a set of criteria to analyse the industry's environment. A summary of scientific researches [15], [16],[17] was used to build a set of criteria for the selected problem. The set included six quantitative criteria describing economic and technical aspects of the selected EGT, and 14 qualitative criteria ones of political, environmental and value-related social aspects. Since the role of the general public in decision-making is growing - when the decisions concern its wellbeing - such criteria as "the effect on sustainable development of society" and "public opinion/support", which express public attitudes and opinion about the impact of technologies, were added to the set.

3) Selecting EGT (alternatives) to make the analysis and to identify the best solution. Eleven EGT were selected for the analysis of alternatives. The alternatives include three gas cogeneration power plants (CHPP), three biomass cogeneration power plants, two geothermal power plants, one operating and one still in design phase, two hydropower plants, two wind power plants (all operates in Lithuania), and two nuclear power plants, still in discussions and consideration phase, in Lithuania and Poland.

4) Determining the values and weights of criteria. The values and weights of criteria were determined based on the results of an expert survey, employing the AHP technique. A two-stage questionnaire was compiled for that purpose and a group of 25 experts selected. The experts included persons working as top managers in the energy industry (with technical, legal, economic expertise). The expert survey was carried out between October 2011 and January 2012. The first stage included using the AHP technique to assess the environment factors of the industry, including institutional/political, technological, economic, environmental and social criteria, and then to determine their values. The second stage determined the values and weights of the criteria that define the EGT.

5) Assessing alternatives using the EGTSELECT-DS, an automated DSS. The design of the EGT-SELECT-DS includes four modules: one to determine the priority and utility of alternatives; one to determine the effect of criteria on the ranking of alternatives; one recommender module; and one sensitivity analysis module.

The system prioritises alternatives and determines their utility, demonstrates the effect of criteria on the final ranking of the alternatives, and displays the result of the sensitivity analysis when the likely effect of environment factors is determined.

\section{Results achieved assessing EGT with the help of EGT-SELECT-DS}

\author{
Determination of criteria weights and \\ values.
}

The weights of institutional/political, economic, social/ethic, technological and environmental factors have been determined with the help of expert judgement and the AHP method ( Fig. 1). Experts believe that economic factors dominate in the choice and assessment of energy generation technologies. But their second priority was the group of environmental factors - another evidence that environmental issues are important. Furthermore, social factors outranked institutional/political factors.

Experts ranked 20 criteria by their importance and then, based on the AHP paired comparison scale, the value of each criterion was determined. 


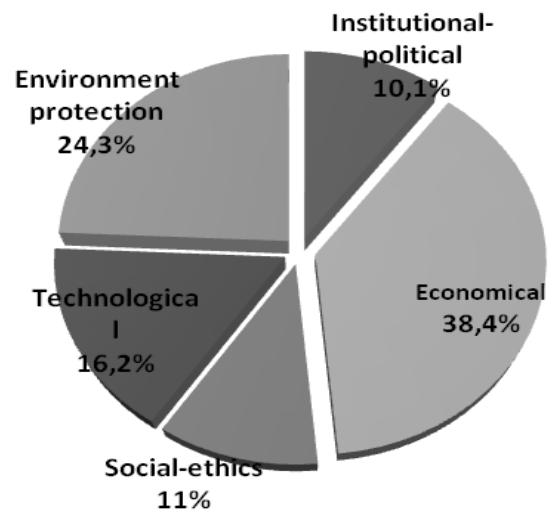

Figure 1. Weights of energy-sector environment factors determined by expert judgement

The research results show that the most significant criteria are cost-effectiveness, production cost, the technology's competitiveness and environmental pollution $\left(\mathrm{SO}_{2}, \quad \mathrm{NO}_{\mathrm{x}}, \mathrm{NH}_{3}\right)$ while the support of government bodies and political organisations were specified as the least important.Table 1 lists the criteria weights as they were ranked during the expert judgement.

Table 1. Ranking of criteria weights

\begin{tabular}{c|l|c}
\hline Priority & \multicolumn{1}{|c}{ Criterion } & Criterion's weight \\
\hline $\mathbf{1}$ & Cost-effectiveness & 0.124 \\
$\mathbf{2}$ & Production cost & 0.01 \\
$\mathbf{3}$ & Technology's competitiveness & 0.087 \\
$\mathbf{4}$ & Environmental pollution (SO2, NOx, NH3) & 0.076 \\
$\mathbf{5}$ & Development cost of technical facilities & 0.074 \\
$\mathbf{6}$ & Use of renewable resources & 0.065 \\
$\mathbf{7}$ & Waste management & 0.058 \\
$\ldots$ & $\ldots \ldots$ & $\ldots$ \\
$\mathbf{1 9}$ & Effect on the industry's sustainable development & 0.020 \\
$\mathbf{2 0}$ & Support of government bodies and political organisations & 0.015 \\
\hline
\end{tabular}

The results of the assessment technologies using EGT-SELECT-DS.

The system automatically solves a problem dealing with the assessment of EGT:

1) ranks the technologies by priority and picks out the best of them;

2) determines the utility degree of a technology taking into account the technology ranked first;

3 ) displays the analysis of the impact of the criteria in the recommender module;

4) for each technology, picks out the criteria that make the biggest impact on its value.

The EGT-SELECT-DS system operates online and is available at http://iti.vgtu.lt/jurate/daugkrit.aspx.

Judging from the results of the assessment of EGT and the sensitivity analysis in the EGT-SELECT-DS, the nuclear technology is the top priority, followed by the biomass technologies. The gas cogeneration power plant ranked the lowest. The result of the assessment is shown in Figure 2. 


\begin{tabular}{|c|c|c|c|c|c|c|c|c|c|c|c|c|c|c|}
\hline & 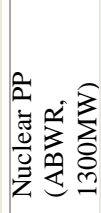 & 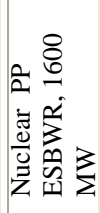 & 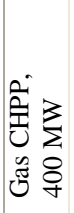 & 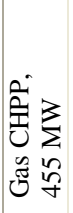 & 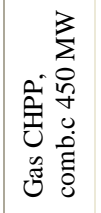 & $\begin{array}{l}\sum_{0}^{1} \\
0 \\
01 \\
0 \\
0 \\
0 \\
0\end{array}$ & 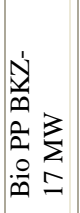 & 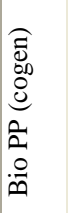 & 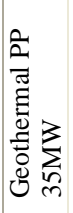 & 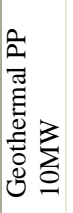 & 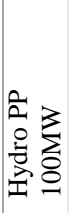 & 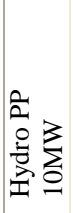 & $\begin{array}{l}\sum_{n}^{3} \\
0 \\
0 \\
0 \\
\vdots \\
\vdots \\
\vdots\end{array}$ & 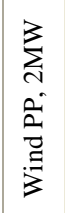 \\
\hline Alternative's weight & 0.134 & 0.131 & 0.049 & 0.047 & 0.046 & 0.073 & 0.071 & 0.071 & 0.061 & 0.062 & 0.072 & 0.07 & 0.057 & 0.056 \\
\hline Alternative's priority & 1 & 2 & 12 & 13 & 14 & 3 & 5 & 6 & 9 & 8 & 4 & 7 & 10 & 11 \\
\hline $\begin{array}{l}\text { Alternative's utility } \\
\text { degree }[\%]\end{array}$ & 99.98 & 97.44 & 36.28 & 35.01 & 34.42 & 54.08 & 53.04 & 52.82 & 45.59 & 45.81 & 53.71 & 52.07 & 42.31 & 41.57 \\
\hline & \multicolumn{14}{|c|}{ The results of the sensitivity analysis of the assessment } \\
\hline Economic & 1 & 2 & 12 & 13 & 14 & 3 & 4 & 5 & 11 & 10 & 6 & 7 & 8 & 9 \\
\hline Environmental & 2 & 1 & 12 & 13 & 14 & 3 & 5 & 6 & 11 & 11 & 4 & 7 & 8 & 9 \\
\hline Value-related /social & 1 & 2 & 12 & 13 & 14 & 3 & 4 & 5 & 11 & 10 & 6 & 7 & 8 & 9 \\
\hline Technological & 1 & 2 & 12 & 13 & 14 & 5 & 6 & 7 & 9 & 8 & 3 & 4 & 10 & 11 \\
\hline Political/institutional & 1 & 2 & 12 & 13 & 14 & 3 & 4 & 5 & 11 & 10 & 6 & 7 & 8 & 9 \\
\hline
\end{tabular}

Figure .2. An example of assessment and sensitivity analysis in the EGT-SELECT-DS system

The rankings and utility degrees are visualised graphically in Figure 3.

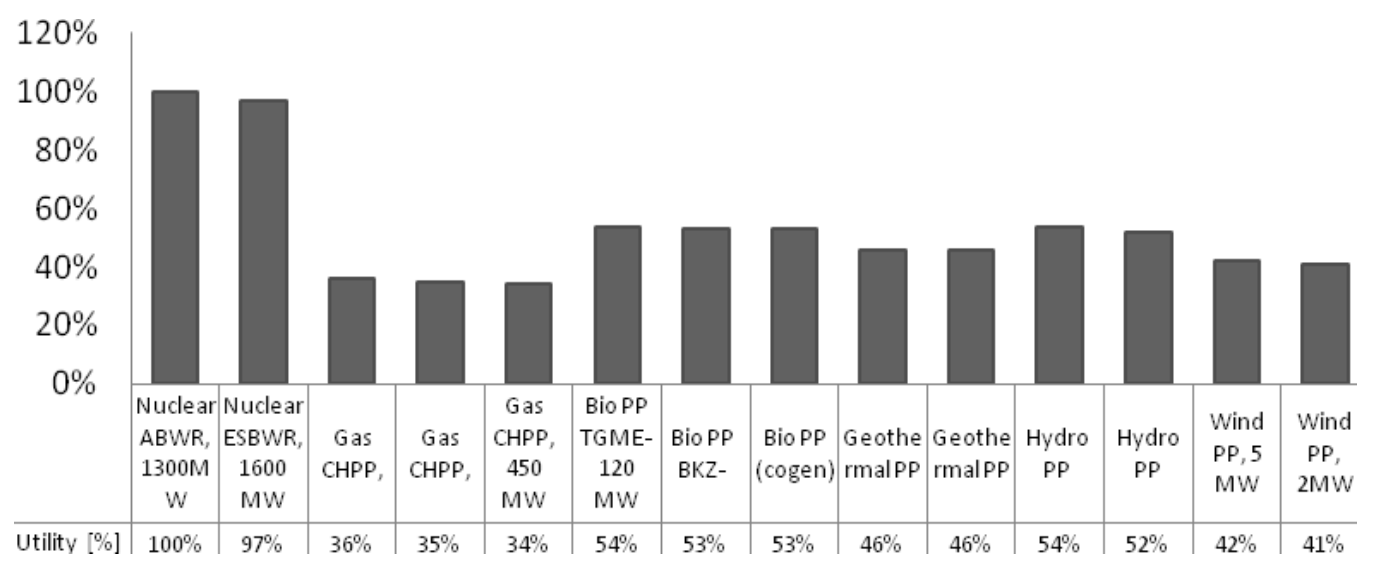

Figure 3. The utility degrees of the alternatives

Automated recommendations in the EGTSELECT-DS system.

The EGT-SELECT-DS system has an additional feature, which is assessing recommendations on the impact of each criterion on the alternative's ranking. An automated selection of the criteria that determine the utility shows that, in case of the nuclear power plant, the most important are such criteria as "Public opinion/support", "Effect on the sustainable development", "Compliance with international commitments", while those important to the gas power plants are "Effect on the sustainable development of society" and "Support of government bodies". In case of the biomass power plants the most significant criterion is "Rated capacity", while in case of the hydropower and geothermal plants the most significant are such criteria as "Rated capacity", "Innovativeness" and "Reliability". An example of recommendations by the EGTSELECT-DSS is shown in Figure 4. 


\begin{tabular}{|c|c|c|c|}
\hline & \multicolumn{3}{|l|}{ Nuclear technologies, EBWR, $1300 \mathrm{MW}$} \\
\hline $\begin{array}{l}\text { Criterion } \\
\text { rank }\end{array}$ & Defining criteria & $\begin{array}{l}\text { Likelihood to } \\
\text { improve the criterion } \\
\text { in question, [\%] }\end{array}$ & $\begin{array}{c}\text { Likely increase in the value } \\
\text { of the alternative, }[\%]\end{array}$ \\
\hline 1 & Public opinion/support & $317 \%$ & $13 \%$ \\
\hline 2 & Effect on the industry's sustainable development & $233 \%$ & $8 \%$ \\
\hline \multirow[t]{2}{*}{3} & Compliance with international commitments & $194 \%$ & $6 \%$ \\
\hline & \multicolumn{3}{|l|}{ Gas CHPP, combined cycle, $450 \mathrm{MW}$} \\
\hline $\begin{array}{l}\text { Criterion } \\
\text { rank }\end{array}$ & Defining criteria & $\begin{array}{c}\text { Likelihood to } \\
\text { improve the criterion } \\
\text { in question, [\%] }\end{array}$ & $\begin{array}{c}\text { Likely increase in the value } \\
\text { of the alternative, [\%] }\end{array}$ \\
\hline 1 & Effect on the sustainable development of society & $300 \%$ & $37 \%$ \\
\hline 2 & $\begin{array}{l}\text { Support of government bodies, political } \\
\text { organisations }\end{array}$ & $411 \%$ & $33 \%$ \\
\hline 3 & Technology's innovativeness & $226 \%$ & $23 \%$ \\
\hline
\end{tabular}

Figure 4. An example of recommendations

Recommendations that are tricky, or even impossible, to implement (make improvements) can also be generated automatically. Recommendations, though, can draw the attention of decision makers not only to economic or technological criteria analysed comprehensively, but also to political or social and ethical criteria, generally seen as less significant; their importance and impact would then be considered, and instruments planned to make the technologies more acceptable and more in demand. For instance, the recommendation for nuclear technologies is to improve 'Public opinion/support', a criterion very significant in attempts to coordinate the development of these technologies with the general public. Making arrangements for informing the public and interaction ought to be part of the technological development process. Any assessments based on expert opinions are somewhat indeterminate. Furthermore, some or other environment factors are in constant transformation: the political situation is changing, environmental requirements are becoming tighter, technologies are being enhanced, more advanced and efficient, technologies discovered and the attitudes held by valuators are changing.

The EGT-SELECT-DS system is a handy tool to make an unbiased analysis of technologies. By varying the values of quantitative criteria, the system can also be efficiently used to assess a range of EGT, to determine their utility, to make other kinds of analysis. They may also be an auxiliary tool to address a range of issues related to infrastructure management, to analyse environment factors, and to find ways to mitigate their impact

\section{Conclusions}

The expert analysis of the impact of environment factors on the value of EGT shows that environmental and valuerelated/social issues are ever-more important and that the development of technologies may be dictated not only by economic factors but also by public attitudes, as well as by the impact on the environment and social wellbeing. The assessment of economic, technological, environmental and social outcomes of market interventions makes it possible to decide whether the selected technologies are beneficial, acceptable and compatible with public attitudes.

The main advantage of the EGT-SELECT$D S$ is their feature that allows comparing different technologies against a uniform set of criteria. This facilitates an unbiased and comprehensive analysis of the technologies which reveals their advantages and disadvantages and the factors that determine these advantages and disadvantages, as well as 
suggests unbiased recommendations to decision makers.

\section{References}

[1] E.K. Zavadskas, Z. Turskis, "Multiple criteria decision making (MCDM) methods in economics: an overview", Technological and economic development of economy, 17(2): 397-427, 2011.

[2] D.C. Morais, A.T. Almeida, "Group decisionmaking for leakage management strategy of water distribution network", Resources, Conservation and Recyclin, 52(2): 441-459, 2007.

[3] A.J. Brito, A.T. Almeida, "Multi-attribute risk assessment for risk ranking of natural gas pipelines", Reliability Engineering \& System Safety, 94(2):187-198, 2009.

[4] J. Zeng, A. Min, N.J. Smith, "Application of a fuzzy based decision making methodology to construction project risk assessment", International Journal of Project Management, 25(6): 589-600, 2007.

[5] O. Barda, J. Dupuis, P. Lencioni, "Multicriteria location of thermal power plants", European Journal of Operational Research, 45:332-346, 1990.

[6] N. Lepkova, E.K. Zavadskas, A. Kaklauskas, "Modelling of facilities management alternatives", International journal of environment and pollution (IJEP), 35(2/3/4): 185-204, 2008.

[7] E. Loken, "Use of multicriteria decision analysis methods for energy planning problems", Renewable and Sustainable Energy Reviews, 11: 1584-1595, 2007.

[8] J.J. Wang, Y.Y. Jing, C.F. Zhang, J.H. Zhao, "Review on multi-criteria decision analysis aid in sustainable energy decision-making", Renewable and Sustainable Energy Reviews, 13: 2263-2278, 2009.
[9] J.Šliogeriene, A. Kaklauskas, E.K. Zavadskas, J. Bivainis, M. Seniut, „Environmet factors of energy companies and their effect on value: analysis model and applied methods", Technological and Economic Development of Economy, 15(3): 490-521, 2009.

[10] T. Kaya, C. Kahraman, .’Multicriteria renewable energy planning using an integrated fuzzy VIKOR \& AHP methodology: The case of Istanbul “, Energy, 35(6): 2517-2527, 2100.

[11] T. Kaya, C. Kahraman, "Multicriteria decision making in energy planning using a modified fuzzy TOPSIS methodology", Expert Systems with Applications, 38: 6577-6585, 2011.

[12] P. Haurant, P. Oberti, M. Muselli, "Multicriteria selection aiding related to photovoltaic plants on farming fields on Corsica island: A real case study using the ELECTRE outranking framework", Energy Policy, 39(2):676-688, 2011.

[13] M.Ch. Das, B. Sarkar, S. Ray, “ A framework to measure relative performance of Indian technical institutions using integrated fuzzy AHP and COPRAS methodology", Socio-Economic

[14] J. Šliogeriene, A. Kaklauskas, D. Štrei-mikiene, M. Bianchi, "Multiple Criteria Decision Support System for the Assessment of Energy Generation Technologies Considering the Dimension of Values", International Journal of Strategic Property Management, 16(4):370-391, 2012.

[15] D. Streimikiene, G. Sivickas G. "The EU sustainable energy policy indicators framework", Environment International, 34(8): 1227-1240, 2008.

[16] International Atomic Energy Agency, 2012. Online: http://www-pub.iaea.org.

[17] NEEDS (New energy externalities Development for Sustainability), 2007. Online:http://www.needsproject.org/RS2b/RS2b_D3.1.pdf 